Articulo producto de investigación

\title{
Valor agregado para el lacto suero de caprino proveniente de agroindustrias lácteas: ácido láctico como alternativa de descontaminación
}

\author{
Alexandra Plata ${ }^{1}$, Sandra Ramírez ${ }^{2}$, Campo Elías Riaño Luna ${ }^{3}$ \\ 1,2. Escuela de Ciencias Básicas Tecnología e Ingeniería, Universidad Nacional Abierta \\ y a Distancia. Bogotá, Colombia \\ 3. Docente asistente de la Escuela de Ciencias Básicas Tecnología e Ingeniería, \\ Universidad Nacional Abierta y a Distancia. Bogotá, Colombia. \\ Correspondencia: campo.riano@unad.edu.co
}

Recibido: 13/03/2013 Aceptado: 21/06/2013

\section{Resumen}

El Lacto suero de leche de caprino (SLC) es un subproducto de bajo valor económico, concebido en Colombia como un desecho industrial con impacto ambiental negativo para los ecosistemas (DBO 60000 ppm y DQO de 80000 ppm). Este trabajo se enfoco en caracterizar el SLC, multiplicar la cepa Lactobacillus Helveticus (LH) 0-0.91-celulas libres y evaluar su pertinencia para la producción de ácido láctico a partir de SLC tratado y enriquecido con tres nutrientes; variables que se estudiaron siguiendo un diseño de cuadro greco latino. Para el efecto se llevaron a cabo 16 cinéticas en un biofermentador intermitente conteniendo 250 mililitros de LSLC en donde la mayor producción de acido láctico-17.72 gramos por litro se logró después de las 50 horas para el medio que contiene extracto de levadura $2,5 \%$, riboflavina $0,6 \%$ y sulfato de amonio $0,45 \%$ operando el biofermentador a $42^{\circ} \mathrm{C}$. De esta forma, al producir ácido láctico se evitaría la contaminación de ecosistemas y se generaría un valor agregado a la industria quesera.

Palabras clave: ácido láctico, cuadro latino, diseño experimental, lactobacillus helveticus, suero de leche de caprino, impacto ambiental

\section{Value added for goat whey from dairy agribusiness: lactic acid as decontamination alternative}

\begin{abstract}
The lacto goat whey (SLC) is a low economic value sub product, considered as industrial waste in Colombia, with negative environmental impact on ecosystems- (BOD 60,000 COD ppm and 80,000 ppm). This study aimed to characterize the SLC, multiply Lactobacillus helveticus (LH) strain and assess its applicability to the production of lactic acid-AL from LSLC treated and enriched with three nutrients. Variables studied following a latin greco square design. For this purpose kinetic 16 were carried out in intermittent biofermenter containing 250 milliliters of LSLC. Increased production of lactic acid (17.72 grams per liter) was achieved after 50 hours using a media containing $2.5 \%$ yeast extract, riboflavin $0.6 \%$ and $0.45 \%$ ammonium sulfate and the biofermenter operating at $42^{\circ} \mathrm{C}$.
\end{abstract}

Keywords: lactic acid, latin square experimental design, Lactobacillus helveticus, goat whey, environmental impact. 


\section{Introducción}

El lactosuero de leche de caprino (LSLC) es el líquido resultante de la elaboración de cuajada o queso, al separarse la caseína y la grasa durante la coagulación (alrededor del 85-90\% del volumen de leche utilizada). Esta constituido aproximadamente por un $93 \%$ de agua, $5 \%$ de lactosa, un poco menos del $1 \%$ de proteína, de las cuales la mitad son proteínas de alto valor nutricional como son; albuminas, globulinas y proteasa-peptona, $0.7 \%$ de minerales, con mayor contenido de sodio, potasio, magnesio, cloruro y fosfato, contiene también las vitaminas hidrosolubles de la leche, la más importante es la riboflavina, también posee pequeñas cantidades de grasa y acido láctico $(\mathrm{AL})$ y su pH se encuentra entre 5-6 (1-24).

Actualmente el suero tiene poca aplicabilidad industrial, los excedentes se convierten en un producto contaminante- (DBO) muy alta, de 40000 a 60000 ppm y una demanda química de oxígeno (DQO) de 50000 a 80000 ppm (15). Más del 90\% de esas demandas se deben a la transformación de la lactosa (20). De allí que la búsqueda de alternativas para el aprovechamiento de este efluente se convierte en necesidad nacional. Una de las alternativas es la obtención de acido láctico (22).

El ácido láctico es de amplio uso en la industria. Debido a sus características se utiliza en la industria alimentaria (en bebidas y como conservante), en farmacia, medicina, textileria, en la industria del cuero y para la producción de plásticos biodegradables (17). El Food Chemical Codex en el año 1996 especifica el uso del AL en alimentos con una pureza del $88 \%$, el AL se puede obtener por síntesis química ó por vía fermentativa (13). Una de las principales dificultades en la producción a gran escala del AL es el costo de las materias primas, siendo de interés encontrar nuevos medios de bajo costo para mejorar la economía del proceso (22).

Los organismos mayores productores de AL pertenecen a las familias Streptococcaceae (géneros Streptococcus, Lactococcus, Leuconostoc, Pediococcus,
Aerobacter y Gemella) y Lactobacillaceae (género Lactobacillus), (9). La familia Lactobacillaceae y en especial los del género Lactobacillus (L. bulgaricus, $L$. helveticus, $L$. delbruekii, etc.), son anaerobios facultativas (no presenta crecimiento superficial o este es escaso), no poseen catalasa, no reducen el nitrato; su metabolismo es fermentativo, cerca del 50\% de su producto final es ácido láctico, su temperatura optima de crecimiento está entre 30$40^{\circ} \mathrm{C}$, en un rango aceptable entre 26 y $46^{\circ} \mathrm{C}$, a un $\mathrm{pH}$ de 4.5-7.2 y es un microorganismo no patógeno (4), razones por la cuales las seleccionamos para este trabajo.

Trabajos pioneros reportan la obtención de 40,78 $\mathrm{g} / \mathrm{L}$ de ácido láctico en 48 horas de fermentación (12). Akerberg (2) utilizando como sustrato harina integral hidrolizada adicionada de glucosa pura reporta concentraciones de ácido láctico de $50 \mathrm{~g} / \mathrm{L}$ con Lactococcus lactis y Lactobacillus casei. Boonme et al. (8), produjo ácido láctico en un medio comercial M17 modificado con lactosa pura y obtuvo concentraciones de $80 \mathrm{~g} / \mathrm{L}$ de ácido láctico y rendimientos de producto de $0,93 \mathrm{~g} / \mathrm{g}$. Sin embargo, la principal desventaja de la producción por la vía fermentativa es el alto costo que ocasionan su aislamiento y purificación (9), por esta razón las investigaciones se han enfocado en la disminución del costo de producción de AL con células libres y/o inmovilizadas (7) e incrementar la pureza óptica del ácido láctico.

Con los referentes anteriores el objetivo de esta investigación fue evaluar la pertinencia del SLC enriquecido con tres nutrientes para la obtención de AL por fermentación utilizando LH 0-0.91-dada su capacidad para convertir en ácido láctico la lactosa proveniente del SLC, para cumplir el objetivo del trabajo se siguió un diseńo experimental de cuadro greco latino.

\section{Materiales y métodos}

Materiales: Lactosuero de leche de caprino desproteinizado, esterilizado y enfriado a $121^{\circ} \mathrm{C}$ y $4^{\circ} \mathrm{C}$ respectivamente filtrado al vacío. 
Microorganismo: Lactobacillus helveticus LH 0-0.91, cepa liofilizada, producida por la Technical Sheet, activada en tubos de vidrio con $10 \mathrm{ml}$ de leche UHT a una temperatura de $42^{\circ} \mathrm{C}$ durante 48 horas en un medio microaerofílico-recipiente cerrado sin oxigeno presente.

Nutrientes: Extracto de levadura, sulfato de amonio y vitamina $\mathrm{B}$, combinación de estos corresponden a los tratamientos: $\mathrm{T}_{1}$ a $\mathrm{T}_{16}$, respectivamente.

Diseño experimental: Se utilizó un diseño de cuadro greco latino $4 \times 4$ (Los tres factores tienen el mismo número de niveles: $\mathrm{K}$, sin interacciones entre los tres factores). El diseńo consiste en agrupar las unidades experimentales en dos direcciones (filas y columnas) y asignar los tratamientos al azar en las unidades, de tal forma que en cada fila y en cada columna estén todos los tratamientos (19). El total de unidades experimentales es igual al cuadrado del numero de tratamientos. Para cuatro tratamientos se requieren 16 unidades. Cuatro temperaturas de fermentación $37^{\circ} \mathrm{C}, 42^{\circ} \mathrm{C}, 48^{\circ} \mathrm{C}$ y $53^{\circ} \mathrm{C}$ y cuatro concentraciones de cada uno de los cuatro nutrientes.
Análisis a realizar: $\mathrm{pH}$ del medio y concentración de acido láctico (determinación de acidez titulable bajo la NTC 4978 de 2001).

Variables de respuesta: Concentración en ácido láctico (g/litro)-absorbancia.

Los coeficientes de rendimiento y la productividad volumétrica fueron determinados en el estado de equilibrio. El estado de equilibrio se estableció cuando los valores evaluados (concentración de ácido láctico, $\mathrm{pH}$ ) no se modificaron significativamente al realizar dos determinaciones consecutivas.

Análisis estadístico: se llevó a cabo un análisis de varianza (ANOVA) de una vía y un análisis de comparación múltiple (Test de Tukey), para comparar la incidencia de los medios sobre el crecimiento del LH y la producción de AL.

\section{Diseño Metodológico:}

Se siguieron las siguientes etapas:

a. Caracterización de la leche y el suero caprino utilizado, Tabla 1.

Tabla 1. Caracterización de la leche caprina y el suero

\begin{tabular}{|c|c|c|c|}
\hline $\begin{array}{l}\text { Análisis } \\
\text { realizado }\end{array}$ & $\begin{array}{l}\text { Leche caprina } \\
\text { nacional }\end{array}$ & $\begin{array}{l}\text { Suero de leche } \\
\text { caprina-nacional }\end{array}$ & $\begin{array}{l}\text { Suero de leche caprina-na- } \\
\text { cional Juárez y col.,1991 }\end{array}$ \\
\hline Cenizas (\%) & 0,94 & 0,45 & $0,69-0,89$ \\
\hline Solidos totales(\%) & 16,3 & 7,47 & $11,70-15,21$ \\
\hline Gravedad especifica & 1,033 & 1,026 & \\
\hline Densidad & 1,034 & 1,003 & \\
\hline Índice de acidez & $16^{\circ} \mathrm{D}$ & $18^{\circ} \mathrm{D}$ & \\
\hline Contenido de caseína ( \%) & 2,85 & 0,89 & \\
\hline $\mathrm{pH}$ & 6,72 & 6,38 & $6,41-6,70$ \\
\hline Contenido de grasa (\%) & 4,7 & 0,51 & $3,00-6,63$ \\
\hline Proteína (\%) & 4,61 & 1,18 & $2,90-4,60$ \\
\hline Lactosa & & & $3,80-5,12$ \\
\hline
\end{tabular}

Fuente: Autores 
b. Filtrado del suero al vacío.

c. Preparación del inoculo y multiplicación del Lactobacillus helveticus- $L H$ - este se hizo crecer en cajas de Petri con PDA a temperatura controlada de $42^{\circ} \mathrm{C}$ por 5 días. De las cajas se tomo una colonia y se hizo crecer en tubos inclinados con PDA a temperatura controlada por 15 minutos, información suministrada por laboratorios Merck S.A.

d. Siembra bajo condiciones de esterilidad por el método de agotamiento o estría, para lo cual las cajas de Petri se introdujeron en un recipiente-medio anaerobio, incubándose el conjunto durante 48 horas a una temperatura de $42^{\circ} \mathrm{C}$.

Para realizar una evaluación visual, se sembró el microorganismo activo en agar MRS, medio selectivo para lactobacillus que posee todos los minerales y compuestos requeridos por esta especie, Figura1.

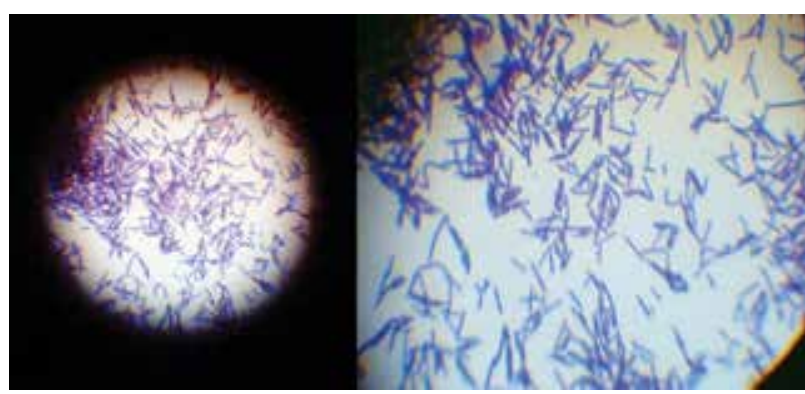

Figura 1. Fotografía microscópica de Lactobacillus helveticus

e. Determinación de las mejores condiciones para la producción de ácido láctico

Las variables estudiadas para la cepa fueron: temperatura de incubación, medios de cultivo y $\mathrm{pH}$ inicial del medio de cultivo. Para el estudio de la temperatura de incubación se ensayaron diferentes valores $\left(37,42,48\right.$ y $\left.53^{\circ} \mathrm{C}\right)$ dentro del intervalo óptimo de crecimiento de LH según se describe en la literatura $(19,23)$ y para el $\mathrm{pH}$ los siguientes valores iniciales: 5; 5,6; 7; 8; 9 y 10 .
Preparados los sustratos se envasaron en erlenmeyers de $500 \mathrm{~mL}$, con un volumen de trabajo de $250 \mathrm{~mL}$ y se sometieron a esterilización por 10 min a $121^{\circ} \mathrm{C}$. Cuando los sustratos se encontraban a temperatura de $30^{\circ} \mathrm{C}$ aproximadamente, se inocularon con la cepa de Lactococcus lactis, la cual antes de la inoculación se adaptó a los diferentes sustratos por tres generaciones en un volumen de $10 \mathrm{~mL}$; en todos los casos se utilizó $10 \%$ de inóculo con respecto al volumen de trabajo (24).

Los tratamientos consistieron en un sustrato básico-lacto suero caprino, más un suplemento de vitaminas y minerales-extracto de levadura, riboflavina y sulfato de amonio, respectivamente. Elaborándose dieciséis medios de cultivo con diferente composición, Tabla 1. Los datos se analizaron mediante análisis de varianza (ANDEVA) para tres factores con efectos fijos. Las diferencias entre los pares de medias de las variables que mostraron diferencias significativas se analizaron mediante la prueba de diferencia significativa honesta de Tukey (DSH). El diseño se analizó con un nivel de confianza del 95\%.

Tabla 2. Definición de tratamientos y convenciones

\begin{tabular}{ccccc|}
\hline $\begin{array}{c}\text { Corrida } \\
\text { experi- } \\
\text { mental }\end{array}$ & $\begin{array}{c}\text { Tempe- } \\
\text { ratura }\end{array}$ & Riboflavina & $\begin{array}{c}\text { Extracto } \\
\text { de levadura }\end{array}$ & $\begin{array}{c}\text { Sulfato de } \\
\text { amonio }\end{array}$ \\
\hline 1 & 37 & 0 & 0 & 0 \\
\hline 2 & 42 & 0,2 & 0 & 0,15 \\
\hline 3 & 48 & 0,4 & 0 & 0,3 \\
\hline 4 & 53 & 0,6 & 0 & 0,45 \\
\hline 5 & 37 & 0 & 1,5 & 0 \\
\hline 6 & 42 & 0,2 & 1,5 & 0,15 \\
\hline 7 & 48 & 0,4 & 1,5 & 0,3 \\
\hline 8 & 53 & 0,6 & 1,5 & 0,45 \\
\hline 9 & 37 & 0 & 2,5 & 0 \\
\hline 10 & 42 & 0,2 & 2,5 & 0,15 \\
\hline 11 & 48 & 0,4 & 2,5 & 0,3 \\
\hline 12 & 53 & 0,6 & 2,5 & 0,45 \\
\hline 13 & 37 & 0 & 3,5 & 0 \\
\hline 14 & 42 & 0,2 & 3,5 & 0,15 \\
\hline 15 & 48 & 0,4 & 3,5 & 0,3 \\
\hline 16 & 53 & 0,6 & 3,5 & 0,45 \\
\hline
\end{tabular}

Fuente: los autores 


\section{Resultados}

Caracterización del suero de leche de cabra entero y descremado. La Tabla 1 presenta resultados de la caracterización bromatológica del suero de leche de cabra utilizado. Los valores observados se encuentran en los rangos típicos de calidad del suero de leche de vaca (16). De acuerdo a estos resultados, el SLC entero tiene una relación proteína/carbohidratos ligeramente menor a 0.5 . Esta es una relación comparativamente alta. La norma mencionada acepta, para el caso de SLC, relaciones mínimas de proteína/carbohidratos del orden de 0.2.

Propagación del inoculo LH: La tinción de Gram y la observación en microscopio electrónico permitió observar la morfología y confirmar la pureza del cultivo y la evaluación visual de las colonias y bacterias.

En la Figura 1 se presenta una fotografía macroscópica de las bacterias sembradas y las colonias de Lactobacillus Helveticus las cuales son redondas, lisas y de color blanco cremoso.
Producción de ácido láctico. En La Figura 1, se muestra la producción de ácido láctico obtenido durante el proceso fermentativo. Según los datos experimentales obtenidos, durante las primeras doce horas se produjo el $35 \%$ de la cantidad total de ácido láctico, después de este tiempo la producción se ve afectada por el crecimiento del microorganismo y el bajo consumo del sustrato logrando estabilizarse a las 48 horas de fermentación con una producción total de $18 \mathrm{~g} / \mathrm{L}$.

El medio 1-solo LSLC tardó ocho horas más que los medios enrriquecidos para lograr el máximo valor de biomasa y AL, y no hubo diferencia estadísticamente significativa entre los recuentos de ambos medios.

El ANDEVA para las tres variables independientes, concentración de extracto de levadura (A), concentración de riboflavina (B) y concentración de sulfato de aluminio (C), no mostraron $\mathrm{P}<0,05$ para la producción de ácido láctico- Tabla 3.

Tabla 3. Análisis de varianza para las variables intervinientes en la producción de AL a partir de LSLC.

\begin{tabular}{lcccccc|}
\hline $\begin{array}{c}\text { Fuentes } \\
\text { de Variación }\end{array}$ & $\begin{array}{c}\text { Grados } \\
\text { de Libertad }\end{array}$ & $\begin{array}{c}\text { Suma } \\
\text { de Cuadrados }\end{array}$ & $\begin{array}{c}\text { Cuadrados medios }= \\
\text { Scuadrados/Grados } \\
\text { de Libertad }\end{array}$ & $\begin{array}{c}\text { FC=Cuadrados } \\
\text { med/Cuadrados } \\
\text { medios del error }\end{array}$ & $\mathbf{F}_{\mathbf{0}, 05}$ & $\mathbf{F}_{\mathbf{0}, 0025}$ \\
\hline Temperatura & 3 & 90,2722688 & 30,0907563 & 20,2460082 & 9,28 & 15,44 \\
\hline $\begin{array}{l}\text { Extracto de } \\
\text { Levadura-A }\end{array}$ & 3 & 19,3515188 & 6,45050625 & 4,3401037 \\
\hline Riboflavina-B & 3 & 29,1255188 & 9,70850625 & 6,53218868 \\
\hline $\begin{array}{l}\text { Sulfato de } \\
\text { amonio-C }\end{array}$ & 3 & 29,1255188 & 9,70850625 & 6,53218868 \\
\hline Error & 3 & 4,45876875 & 1,48625625 & \\
\hline Total & 15 & 172,333594 & 57,4445313 & \\
\hline
\end{tabular}

Fuente: los autores 


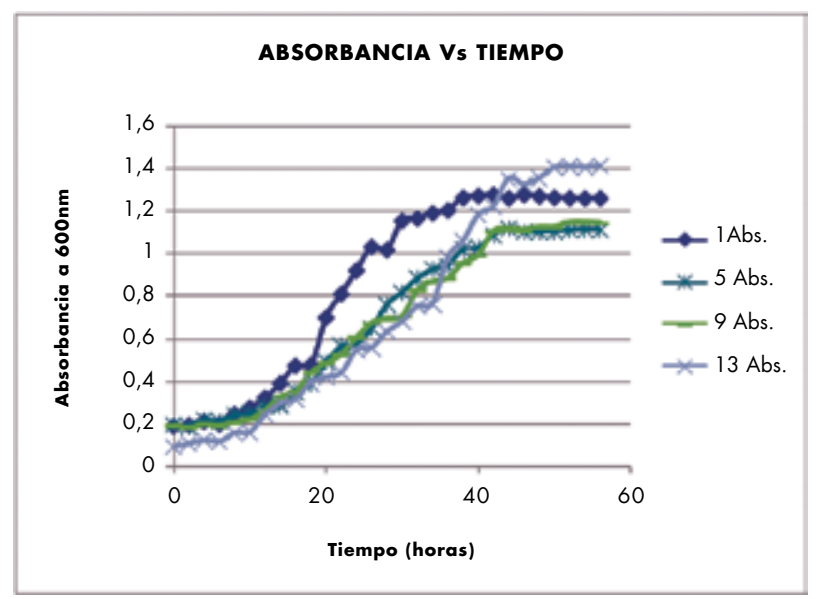

Figura 2. Comparación de resultados de absorbancia ensayos 1 , 5,9 Y 13

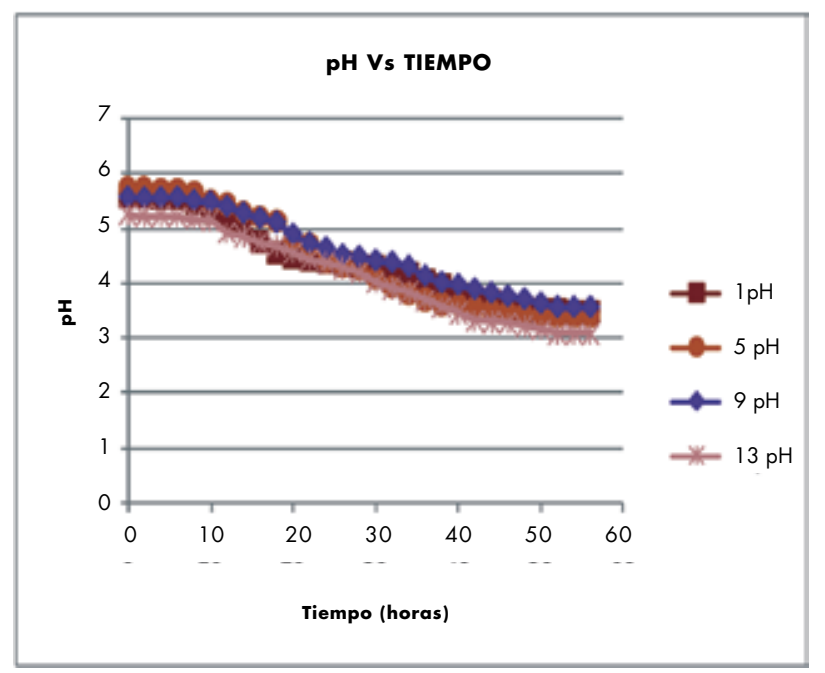

Figura 3. Comparación de resultados de pH ensayos 1, 5, 9 Y 13

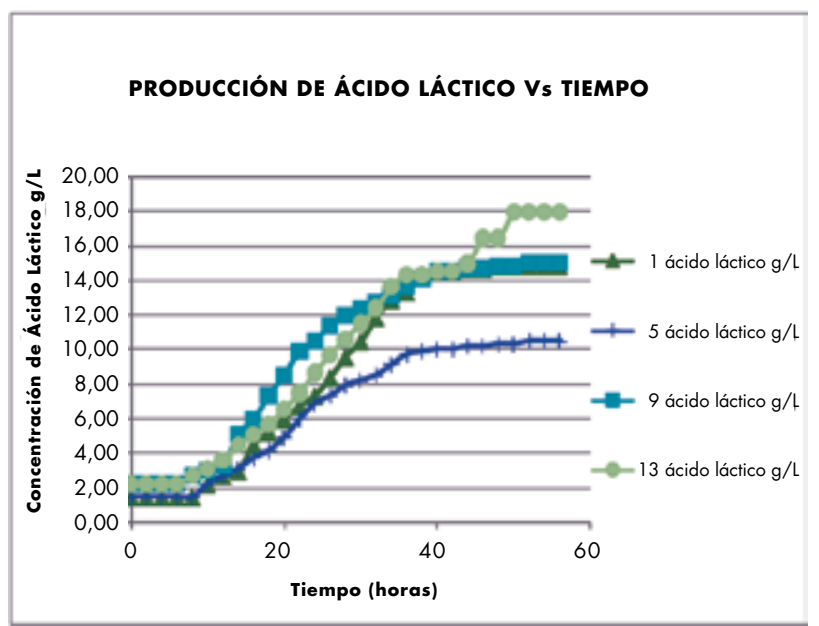

Figura 4. Comparación en la producción de ácido Láctico g/L ensayos $1,5,9$ y 13

\section{Discusión}

El LSLC es un subproducto de muy bajo valor económico, concebido en general en Colombia como un desecho industrial, inclusive con un alto potencial de impacto ambiental negativo. Los resultados presentados documentan la factibilidad para la producción de ácido láctico a partir de este compuesto.

Se comprobó que la temperatura es fuente de variación para la respuesta, resultado comprobado experimentalmente; la concentración de ácido láctico obtenida en los ensayos realizados a $48^{\circ} \mathrm{C}$ fue menor que la concentración obtenida en los ensayos realizados a $38^{\circ} \mathrm{C}$ y $42^{\circ} \mathrm{C}$ respectivamente. $\mathrm{La}$ temperatura óptima comprobada en este trabajo fue de $42^{\circ} \mathrm{C}$, acorde con lo reportado por otros autores $(20,23)$.

Por otra parte, el extracto de levadura no fue fuente de variación estadísticamente significativa. Sin embargo, los ensayos que contenían un mayor porcentaje de extracto de levadura generaban una mayor producción de ácido láctico, lo que nos permite concluir que dicho componente tiene mayor incidencia que el sulfato de amonio y la riboflavina, sin demeritar la función de estos últimos para enriquecer el medio para la producción de este metabolito.

Del análisis estadístico de los datos experimentales se concluye que las fuentes de carbono y de sales evaluadas no tuvieron efecto significativo ( $\mathrm{p}>$ $0,05)$ sobre el crecimiento de la cepa LH 0-0.91, por lo tanto en los trabajos de optimización-posteriores se utilizará un nivel inferior de cada una de las fuentes.

Finalmente, se pudo concluir que el LSLC es un sustrato con muy buen potencial para ser utilizado en la producción de AL, aún sin la adición de extracto de levadura. Sin embargo, cuando se utiliza como complemento extracto de levadura se pueden obtener las más altas concentraciones en AL, las más altas conversiones de sustrato, los mayores rendimientos en producto y las mejores producti- 
vidades volumétricas. El uso de este sustrato podría disminuir los costos operacionales en más del $50 \%$, comparado con el uso de sustratos puros, $y$ daría además un valor agregado muy interesante a este residuo que se deja perder en el campo.

\section{Referencias}

1. Altiok, D. Kinetic Modelling of Lactic Acid Production from Whey. Master of Science. Izmir, Turkey; Izmir Institute of Technology, Food Engineering; 2004.

2. Akeberg, C.; K. Hofvendahl; G. Zacchi \& Hahn, H. Modelling the influence of $\mathrm{pH}$, temperature, glucose and lactic acid concentrations on the kinetics of lactic acid production by Lactococcus lactis ssp. lactis ATCC 19435 in whole _ wheat flour. Applied Microbiology and Biotechnology. 1998; 49: 682 - 690.

3. Aguirre-Eskauriatza, J. Producción de proteína liofilizada y biomasa de Lactobacillus casei BPG4 liofilizada, a partir de suero de leche de cabra. Tesis de Maestría. México: Tecnológico de Monterrey; 2008.

4. Alais, C. Ciencia de la leche. Principios de técnica lechera. México: CECSA; 1970.

5. Altiok, D., Tokatli, F. \& Harsa, S. Kinetic modeling of lactic acid production from whey by Lactobacillus casei (NRRL B-441). Journal of Chemical Technoogy and Biotechnology. 2006;81: 1190-1197.

6. Association Of Official Agricultural Chemists. Official Methods Of Analysis.13th ed.: Washington, 1980.

7. Betancur,J., Abad,P., Arias, M. \& Restrepo, B. Inmovilización de lactobacillus helveticus en soportes vítreos obtenidos por tecnología sol-gel.Boletín de la Sociedad Española de Cerámica y Vidrio. 2003; 42,(2): 79-83.

8. Boonmee, M., Leksawasdi, N.; Bridge, W. \& Rogers, P. Batch and Continuous culture of Lactococcus lactis NZ133: Experimental data and model development. Biochemical Engineering Journal. 2003;14(2): 127-135.

9. Estela, W; Rychtera, M, Melzoch, K, et al. Producción de acido láctico por Lactobacillus plantarum L10 en cultivos batch y continuo. Rev. peru biol. 2007; 14(2):271-276.

10. Food Chemical Codex. $7^{\text {th }}$ ed. The United States Pharmacopeial Convention. 2010.
11. Foo, E. L.; H. G. Griffin; R. Mollby \& Hedén, C. G. The Lactic Acid Bacteria: United Kingdom: Horizon Scientific Press, 1993:89 - 91

12. Fu, W. \& Mathews, A. Lactic acid production from lactose by Lactobacillus plantarum: Kinetic model and effects of $\mathrm{pH}$, substrate, and oxygen. Science Direct. Biochem Eng J. 1999; 3: $163-170$.

13. Goksungur, Y \& Guvenc, U. Production of lactic acid from beet molasses by calcium alginate immobilized Lactobacillus delbrueckii. Journal of Chemical Technology and Biotechnology. 1999; 74: 131 - 136.

14. Ha, M. \& Kim, S. Kinetics analysis of growth and lactic acid production in $\mathrm{pH}$-controlled batch cultures of Lactobacillus casei $\mathrm{KH}-1$ using yeast extract/corn steep liquor/glucose medium. Journal of Bioscience and Bioengineering. 2003; 96(2):134-140.

15. Jin B, Yin P, Ma Y, Zhao L, J. Ind. Microbiol. Production of lactic acid and fungal biomass by Rhizopus fungi from food processing waste streams. Biotechnol. 2005: 32-678.

16. Juarez, M., Ramos, M. \& Martín, C. Quesos españoles de leche de cabra. Madrid: FESLAC; 1991.

17. Lederberg, J. (Editor). Encyklopedia of Microbiology. $2^{\text {a }}$ ed. New York :The Rockefeller University, 1992; (3): 1 - 17.

18. Microbiología industrial. (s.f). Disponible en línea: www.unavarra.es/genmic/micind-2-2.htm. (23 de junio de 2007).

19. Montgomery, D. \& Runger, G. Probabilidad y Estadística. $2^{\text {a }}$ ed. México: Mc Graw Hill Intermericana Editores; 2000.

20. Ocampo, O., Urbina C.E., Juárez, C., Ruiz, N. \& Galíndez, J. Depuración del suero común cultivo mixto de levaduras, utilizando un sistema por lote alimentado y alimentado repetido. Tecnología Láctea Latinoamericana. 2000, (20), 44-52.

21. Prescott, S. \& Duna, C. Microbiología Industrial. 2a . Madrid: Aguilar, S. A. de Ediciones; 2000.

22. Rojan, P., Madhavan, N., and Pandey, A. Solid-state fermentation of L-lactic acid production from agro wastes using Lactobacillus delbrueckii. Process Biochemistry. 2006; (41), 759-763.

23. Serna, L., and A. Rodríguez. Lactic acid production by a strain of Lactococcus lactis subsp. lactis isolated from sugar cane plants. Elect. J. Biotechnol. 2006, 9:40-45.

24. Urribarrí, L. Producción de ácido láctico a partir de suero de leche, utilizando Lactobacillus helveticus en cultivo continuo. Revista Científica. Universidad del Zulia. 2004; 14(4). 